\title{
Myositis-Like Syndrome Revealing Hypothyroidism
}

\section{Bouomrani S*, Regaieg N, Belgacem N, Ben Hamed M, Lassoued N, Trabelsi S, Baïli H}

Department of Internal Medicine, Military Hospital of Gabes, Tunisia. salembouomrani@yahoo.fr

*Corresponding Author: Dr. Salem Bouomrani, MD, PhD, Department of Internal Medicine, Military Hospital of Gabes, Gabes 6000, Tunisia.

\section{Abstract}

Introduction: Muscular involvement during hypothyroidism is rare and often infra-clinical. Symptomatic forms simulating authentic inflammatory myopathy remain exceptional and difficult to diagnose. We report a particular observation of primary hypothyroidism presenting initially by a "myositis-like" syndrome.

Case Report: A 66-year-old woman with no medical history was explored for myalgia associated with proximal muscular weakness, which had been evolving for the past month, with an increase in muscle enzymes: CPK at $1570 \mathrm{IU} / \mathrm{l}$ and LDH at $607 \mathrm{IU} / \mathrm{l}$. She was sent to us for suspicion of polymyositis. The electromyogram was noncontributory and the muscle MRI was without abnormalities. Anti-nuclear antibodies and anti-soluble antigen antibodies were negative.

The thyroid assessment showed TSH at $15.45 \mu \mathrm{IU} / \mathrm{ml}$, fT4 at $10.55 \mathrm{pmol} / \mathrm{l}$, anti-thyroglobulin antibodies positive at $1000 \mathrm{IU} / \mathrm{ml}$, and anti-thyroperoxidase positive at $488.5 \mathrm{IU} / \mathrm{ml}$ confirming the diagnosis of Hashimoto's thyroiditis. Under thyroxine, the evolution was favorable with disappearance of muscular complaints and normalization of muscular enzymes.

Conclusion: The "myositis-like" syndrome is an exceptional presentation of hypothyroidism that represents a real diagnostic challenge for the clinician, especially since a true combination of thyroiditis and myositis is possible. It is recommended to screen for thyroid dysfunction in front of presentation suggestive of myositis, especially that this myosite-like syndrome may be the first inaugural manifestation of hypothyroidism.

Keywords: Myosite-like syndrome, hypothyroidism, CPK, myositis, thyroiditis.

\section{INTRODUCTION}

Muscular involvement during hypothyroidism is rare and often infra-clinical [1,2]. It may be of the type of myalgia, cramps, muscle weakness, muscle hypertrophy, and increased muscle enzyme, particularly creatine-phosphokinase (CPK) [3], and the most characteristic clinical presentation of the specific muscle involvement of hypothyroidism is the Hoffmann's syndrome associating muscular stiffness and hypertrophy [4].

Rarely, symptomatic forms of myopathy of hypothy roidism can be very obvious and simulate true primary inflammatory myopathy $[1,2,5]$. These socalled "myositis-like syndrome" presentations remain exceptional and represent a real challenge for the clinician $[1,6]$.
We report a particular observation of primary hypothyroidism revealed by a myositis-like syndrome.

\section{CASE REPORT}

A 66-year-old woman with no medical history was explored for myalgia associated with proximal muscular weakness, which had been evolving for the past month, with an increase in muscle enzymes in the city: CPK at $1570 \mathrm{IU} / \mathrm{l}$ and lactate dehydrogenase (LDH) at $607 \mathrm{IU} / \mathrm{l}$.She was sent to us for suspicion of polymyositis. No medication, trauma or recent infections were noted.

The clinical examination noted a proximal muscle weakness at the four limbs, with muscle testing at $4-/ 4+$. No neurological signs or skin lesions were noted. The rest of the somatic examination was without abnormalities. The biological assessment 
confirmed rhabdomyolysis with CPK at 1890 IU/L and LDH at 786 IU/l. The rest of the basic biological tests waswithout abnormalities (blood cell count, erythrocyte sedimentation rate, C-reactive protein, serum protein electrophoresis, creatinine, ionogram, liver enzymes, lipid parameters, troponin Ic, and urine analysis). The chest X-ray and the electrocardiogram were also without abnormalities. The electromyogram showed nonspecific myogenic changes. The immunological assessment of primary inflammatory myopathies was negative (anti-nuclear antibodies and anti-soluble antigens antibodies). MRI of the quadriceps muscles was also without abnormalities. Thus the diagnosis of primary inflammatory myopathy was eliminated. The thyroid status showed TSH at $15.45 \mu \mathrm{IU} / \mathrm{ml}$ and fT4 at 10.55 pmol/l. The thyroid immunological test confirmed the diagnosis of Hashimoto's thyroiditis with positive anti-thyroglobulin antibodies at $1000 \mathrm{IU} / \mathrm{ml}$ and anti-thyroperoxidase at $488.5 \mathrm{IU} / \mathrm{ml}$. The evolution was favorable with the disappearance of myalgia and muscle weakness and normalization of muscle enzymes one month after the normalization of TSH under thyroxin: CPK at $86 \mathrm{IU} / \mathrm{l}$ and LDH at $240 \mathrm{IU} / \mathrm{l}$.

\section{Discussion}

The "myositis-like" syndrome defined as a muscular weakness associated with the elevation of muscle enzymes [2,7] is an exceptional manifestation of hypothyroidism [6]. Indeed, Madariaga MG's 2002 review of the literature, collecting all cases of myositislike syndrome reported during hypothyroidism over a period of 25 years (1975-2000), found only 32 cases [ 7]. Similarly, in the large rheumatologic series of Leverenz D, of 192 patients referred for CPK> 1000 IU/l with myositis suspicion, hypothyroidism was at the origin of this syndrome "myositis-like" only in four patients, $2 \%$ [8].

This syndrome may be the first sign of hypothyroidism $[1-3,9]$, and may remain the sole manifestation of this endocrinopathy [10].

The clinic can simulate point by point a true polymyositis [11], and more rarely skin signs may be added simulating even dermatomyositis $[12,13]$. This explains why, often, the hypothyroidism presenting with a myositis-like syndrome remains for a long time misdiagnosed and mismanaged [3].

These myositis-like presentations of hypothyroidism have been reported in both adults [1-3] and children [8] and all muscles can be affected, but those of the shoulder and pelvic girdles are most commonly involved [3]. More rarely forms of diffuse myopathy with paraspinal muscle involvement can be seen, leading to severe presentations with even a camptocormia [2].

The electromyogram can be normal in 50\% of cases; otherwise it can reveal minor and nonspecific myopathic changes [7]. Similarly, muscle biopsy is not contributory to the diagnosis, it shows nonspecific histological lesions such as: type II fiber atrophy, type I fiber hypertrophy, necrosis, central nuclei disposition, inflammatory infiltrate and the presence of core-like structures [7]. Sometimes perivascular lymphocyte infiltration is important, suggesting an authentic primary myositis [12]. The diagnostic challenge is even more difficult to solve, as the combination of hypothyroidism and primary inflammatory myopathy type polymyositis or dermatomyositisis possible [14-16].

Several authors recommend, to systematically screen for hypothyroidism in front of any muscular complaint that is not proven, and in particular in front of a myositis-like syndrome. This screening is recommended even in the absence of signs suggestive of hypothyroidism, since these signs can be masked by those of the primary myositis, especially in rapid and very evolutionary myositis [14]. Thyroid explorations, in front of a myositis-like syndrome, can exceptionally reveal, in addition to hypothyroidism, an associated thyroid cancer [16].

\section{ConClusion}

Myositis-like syndrome is an exceptional and unusual manifestation during hypothyroidism. It represents a real diagnostic challenge for the clinician, especially as the association of thyroiditis and authentic myositis exists. It is therefore necessary to request thyroid tests in front of any table suggestive of myositis, especially since this presentation may be the inaugural manifestation of hypothyroidism.

\section{REFERENCES}

[1] Aslam H, Sayeed MA, Qadeer R, Afsar S. Hypothyroidism simulating as polymyositis. J Pak Med Assoc. 2015;65(5):559-60.

[2] Kim JM, Song EJ, Seo JS, Nam EJ, Kang YM. Polymyositis-like syndrome caused by hypothy roidism, presenting as camptocormia. Rheumatol Int. 2009;29(3):339-42. 
[3] Ciompi ML, Zuccotti M, Bazzichi L, Puccetti L. Polymyositis-like syndrome in hypothyroidism: report of two cases. Thyroidology. 1994; 6(1): 33-6.

[4] Chung J, Ahn KS, Kang CH, Hong SJ, Kim BH. Hoffmann's disease: MR imaging of hypothyroid myopathy. Skeletal Radiol. 2015; 44(11): 1701-4.

[5] Jiskra J, Límanová Z. Myopathy syndrome in undiagnosed hypothyroidism. VnitrLek. 2001; 47(9): 642-6.

[6] Cabili S, Pines A, Kaplinsky N, Frankl O. Hypothyroidism masquerading as polymyositis. Postgrad Med J. 1982; 58 (683): 545-7.

[7] Madariaga MG. Polymyositis-like syndrome in hypothyroidism: review of cases reported over the past twenty-five years. Thyroid. 2002; 12(4): 331-6.

[8] Leverenz D, Zaha O, Crofford LJ, Chung CP. Causes of creatine kinase levels greater than $1000 \mathrm{IU} / \mathrm{L}$ in patients referred to rheumatology. ClinRheumatol. 2016; 35(6): 1541-7.

[9] Sbrocchi AM, Chédeville G, Scuccimarri R, Duffy CM, Krishnamoorthy P. Pediatric hypothyroidism presenting with a polymyositis-like syndrome and increased creatinine: report of three cases. J PediatrEndocrinolMetab. 2008; 21(1): 89-92.
[10] Madhu SV, Jain R, Kant S, Prakash V, Kumar V. Myopathy presenting as a sole manifestation of hypothyroidism. J Assoc Physicians India. 2010; 58: 569-70.

[11] Salvarani C, Marcello N, Macchioni P, Guidetti D, Rossi F, Iori I, et al. Hypothyroidism simulating polymyositis. Report of two cases. Scand J Rheumatol. 1988; 17(2): 147-9.

[12] Matayoshi T, Omi T, Mayumi N, Kawana S. Hashimoto's thyroiditis with clinical manifestations resembling dermatomyositis: a case report. J Nippon Med Sch. 2014; 81(2): 106-9.

[13] Newman AJ, Lee C. Hypothyroidism simulating dermatomyositis. J Pediatr. 1980;97(5):772-4.

[14] Lukjanowicz M, Bobrowska-Snarska D, Brzosko M. Coexistence of hypothyroidism with polymy ositis or dermatomyositis. Ann Acad Med Stetin. 2006; 52Suppl 2:49-55.

[15] Wang H,Li H, Kai C, DengJ.Polymyositis associated with hypothyroidism or hyperthyroidism: two cases and review of the literature. ClinRheumatol. 2011;30(4):449-58.

[16] Smith CJ, Staniland JR. A difficult case of inflammatory myositis. Age Ageing. 2003; 32(3): 351-2.

Citation: Bouomrani S, Regaieg N, Belgacem N, et al. Myositis-Like Syndrome Revealing Hypothyroidism. Archives of Diabetes and Endocrine System. 2018; 1(2): 1-3.

Copyright: (c) 2018 Bouomrani S, Regaieg N, Belgacem N, et al. This is an open access article distributed under the Creative Commons Attribution License, which permits unrestricted use, distribution, and reproduction in any medium, provided the original work is properly cited. 